\title{
Comprehensive transcriptome analysis of grafting onto Artemisia scoparia W. to affect the aphid resistance of chrysanthemum (Chrysanthemum morifolium T.)
}

\author{
Xue-ying Zhang, Xian-zhi Sun*, Sheng Zhang, Jing-hui Yang, Fang-fang Liu and Jie Fan
}

\begin{abstract}
Background: Aphid (Macrosiphoniella sanbourni) stress drastically influences the yield and quality of chrysanthemum, and grafting has been widely used to improve tolerance to biotic and abiotic stresses. However, the effect of grafting on the resistance of chrysanthemum to aphids remains unclear. Therefore, we used the RNASeq platform to perform a de novo transcriptome assembly to analyze the self-rooted grafted chrysanthemum (Chrysanthemum morifolium T. 'Hangbaiju') and the grafted Artermisia-chrysanthemum (grafted onto Artemisia scoparia W.) transcription response to aphid stress.

Results: The results showed that there were 1337 differentially expressed genes (DEGs), among which 680 were upregulated and 667 were downregulated, in the grafted Artemisia-chrysanthemum compared to the self-rooted grafted chrysanthemum. These genes were mainly involved in sucrose metabolism, the biosynthesis of secondary metabolites, the plant hormone signaling pathway and the plant-to-pathogen pathway. KEGG and GO enrichment analyses revealed the coordinated upregulation of these genes from numerous functional categories related to aphid stress responses. In addition, we determined the physiological indicators of chrysanthemum under aphid stress, and the results were consistent with the molecular sequencing results. All evidence indicated that grafting chrysanthemum onto A. scoparia W. upregulated aphid stress responses in chrysanthemum.

Conclusion: In summary, our study presents a genome-wide transcript profile of the self-rooted grafted chrysanthemum and the grafted Artemisia-chrysanthemum and provides insights into the molecular mechanisms of C. morifolium T. in response to aphid infestation. These data will contribute to further studies of aphid tolerance and the exploration of new candidate genes for chrysanthemum molecular breeding.
\end{abstract}

Keywords: Chrysanthemum, Grafting, Aphid stress, Gene expression, RNA-Seq

\section{Background}

Chrysanthemum (Chrysanthemum morifolium T.) is an ornamental plant with a high economic value worldwide $[1,2]$; it has a long cultural history in China, where it has been used in tea and medicine, and has diverse functions, including preventing tumorigenesis and reducing blood stress [3]. However, C. morifolium T. is susceptible to aphids (Macrosiphoniella sanbourni), from seedling establishment to flowering, which reduces plant

\footnotetext{
* Correspondence: sunxianzhi@126.com

College of Horticulture Science and Engineering, Shandong Agricultural University, 61 Daizong Street, Taian 271018, China
}

vegetative and reproductive growth [4]. In addition, severe aphid infestations can also result in serious economic losses in chrysanthemum production worldwide.

Studies have shown that grafting has been used in horticulture in China since before $2000 \mathrm{BC}[5,6]$. Additionally, grafting is still widely used today to improve the abiotic stress tolerance of many types of plants, for example, in the cultivation of grape vines, apples, Prunus spp. and vegetables, by regulating many metabolic pathways and stress response processes [7, 8]. Furthermore, previous research has suggested that the herbaceous genus Artemisia provides a useful rootstock for 
enhancing abiotic stress tolerance in chrysanthemum [9-11]. However, the exact mechanisms and functions of this rootstock under biotic stress remain unclear. During grafting, a scion and rootstock are cut and adhered to each other and then undergo a series of morphological, physiological and biochemical changes [12]. The inherent genetic characteristics, tissue structures, and physiological and biochemical resistance mechanisms are intertwined, thereby enabling the grafted plants to exhibit enhanced resistance to pests and diseases [13].

Extensive efforts have been made to explicate the mechanism of aphid resistance in chrysanthemum. $\mathrm{Nu}$ merous transcription factors have been reported to act as regulators of the response to aphid herbivory in chrysanthemum [14-16]. However, the gene expression profiles in response to aphid feeding are rarely reported in grafted chrysanthemum. During aphid infestation, a series of plant defense responses, including transcriptional regulation, plant hormone signal transduction, and the expression of different kinds of defense genes, are induced [17]. Moran [18] observed that genes associated with signaling, pathogenesis-related (PR) responses, and calcium-dependent signaling are the essential components of the aphid response profile in Arabidopsis thaliana. The plant hormones salicylic acid (SA), jasmonic acid (JA), and ethylene (ET) play key roles as signaling molecules during both abiotic and biotic stresses, including plant-aphid interactions [18-20]. In interactions between Myzus persicae and A. thaliana, the SA signaling pathway is activated, and the expression of genes such as $P R$ genes (i.e., $\beta$-1,3-glucanase and chitinases) associated with the signaling pathway increases [21]. Plants can also activate the biosynthesis of secondary metabolites (alkaloids, terpene, phenolics, and flavonoids) that have antixenotic or antibiotic properties to deter herbivore growth, development, and reproduction [22].
In the present study, we aimed to identify the differentially regulated aphid-responsive and defense-related genes between the self-rooted grafted chrysanthemum $(\mathrm{Cm} / \mathrm{Cm})$ and grafted Artemisia-chrysanthemum $(\mathrm{Cm} /$ As) during aphid infestation. Our findings will enrich our knowledge of the mechanisms underlying the improvements in aphid resistance caused by grafting.

\section{Results}

\section{Aphid population statistics}

As shown in Fig. 1 and Table 1, aphid settlement was similar in the $\mathrm{Cm} / \mathrm{Cm}$ and $\mathrm{Cm} /$ As plants in the first 3 $\mathrm{d}$ after aphid infestation. On the 5th day, the aphid number between the $\mathrm{Cm} / \mathrm{Cm}$ and $\mathrm{Cm} / \mathrm{As}$ plants showed a significant difference (Table 1). Then, the aphids on $\mathrm{Cm}$ / As slowly increased, whereas the aphid number on $\mathrm{Cm}$ / Cm exhibited a steady and continuous increase from the 5th day to the 10th day. Thus, we hypothesized that the aphid-responsive genes that mediate defense events in the first $4 \mathrm{~d}$ of aphid feeding may be crucial to chrysanthemum resistance mechanisms. To unravel the molecular mechanisms involved in aphid resistance, three sampling points during a 4-d experimental period were selected for transcriptome analysis.

\section{Physiological changes in chrysanthemum under aphid stress}

As shown in Fig. 5a, a higher concentration of soluble sugar was observed in $\mathrm{Cm} / \mathrm{As}$ than in $\mathrm{Cm} / \mathrm{Cm}$ at the same time point after infestation. Furthermore, flavonoid accumulation was observed in the leaves of $\mathrm{Cm} / \mathrm{As}$ and $\mathrm{Cm} / \mathrm{Cm}$, and a higher concentration of flavonoids was observed in $\mathrm{Cm} /$ As than in $\mathrm{Cm} / \mathrm{Cm}$ (Fig. 6b). As shown in Fig. 6c, the activity of PAL in Cm / As was significantly increased by aphid infestation and substantially higher than that in $\mathrm{Cm} / \mathrm{Cm}$. Additionally, the CAT activity in $\mathrm{Cm} / \mathrm{As}$ and $\mathrm{Cm} / \mathrm{Cm}$ decreased rapidly by 69.5 and $83.7 \%$ (Fig. 7b) within $6 \mathrm{~h}$ of infestation with

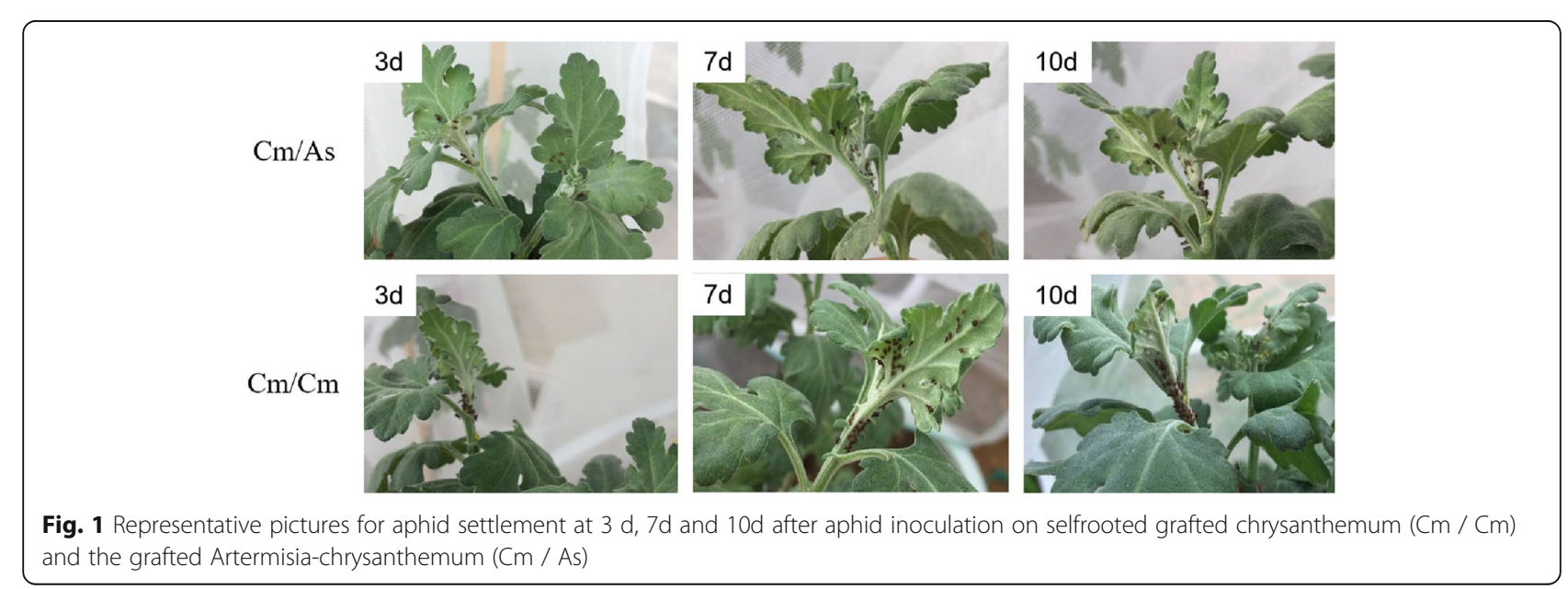


Table 1 Average number of aphids in the $\mathrm{Cm} / \mathrm{Cm}$ and $\mathrm{Cm} / \mathrm{As}$

\begin{tabular}{lllllll}
\hline Cultivars & \multicolumn{5}{l}{ No. of aphids at different days after inoculation } & \\
\cline { 2 - 6 } & $1 \mathrm{~d}$ & $3 \mathrm{~d}$ & $5 \mathrm{~d}$ & $7 \mathrm{~d}$ & $9 \mathrm{~d}$ & $10 \mathrm{~d}$ \\
\hline $\mathrm{Cm} / \mathrm{As}$ & $23.5 \pm 1.0$ & $37.2 \pm 4.3$ & $41.4 \pm 9.1^{\mathrm{b}}$ & $42.9 \pm 6.7^{\mathrm{B}}$ & $52.9 \pm 9.1^{\mathrm{B}}$ & $52.6 \pm 4.4^{\mathrm{B}}$ \\
$\mathrm{Cm} / \mathrm{Cm}$ & $21.6 \pm 0.6$ & $40.0 \pm 4.6$ & $50.7 \pm 7.8^{\mathrm{a}}$ & $78.9 \pm 3.7^{\mathrm{A}}$ & $100.0 \pm 3.6^{\mathrm{A}}$ & $119.8 \pm 6.8^{\mathrm{A}}$ \\
\hline
\end{tabular}

Data were mean \pm standard error; lowercase and capital letters represented significant differences at $p<0.05, p<0.01$

aphids, and the activity of LOX (Fig. 7d) was significantly increased by aphid infestation and higher in $\mathrm{Cm} /$ As than in $\mathrm{Cm} / \mathrm{Cm}$.

\section{Transcriptome sequencing and assembly}

In total, $126.66 \mathrm{~Gb}$ high-quality sequences were obtained from the transcriptome sequencing of the leaves of the $\mathrm{Cm} / \mathrm{Cm}$ and $\mathrm{Cm} / \mathrm{As}$ plants under aphid-infestation conditions, ranging from 6.25 to $8.16 \mathrm{~Gb}$ per sample. The average error rates of the sequences were $0.03 \%$ and more than 91\% (Additional file 1: Figure S1). The assembled sequence data for these raw reads were deposited at the National Center for Biotechnology Information (NCBI) Sequence Read Archive (SRA, http://www.ncbi. nlm.nih.gov/Traces/sra) under the accession number SRP217705. The sequencing data were assembled into 147,307 transcripts with lengths ranging from 201 to 38, 240 bases (mean length $=825$ bases, and median length $=$ 579 bases). As a result, 400,234 unigenes were obtained (mean length $=894$ bases, and median length $=657$ bases). The total length of the unigenes was $35.8 \mathrm{Mb}$ (357,942,294 bases). (Additional file 1: Figure S2). All of these data indicated that the throughput was sufficiently high and the assemble quality was very better for the following analysis.

\section{Gene annotation and functional classification}

In total, 400,232 unigenes (59.0\% of the total unigenes) were annotated in the databases in this study. Most of those unigenes were annotated in the Swiss-Prot database (Table 2). Regarding to GO classification, the largest amount of annotations was in the Biological Process (BP) category, for which cellular process, metabolic process and single-organism process were the top $3 \mathrm{GO}$ terms; the second largest amount of annotations was in the Cellular Component (CC) category, and the third largest amount of annotations was in the Molecular Function (MF) category. Furthermore, we compared unigenes with the KOG classification, the top 3 classes were (O) Posttranslational modification, protein turnover, chaperones, (R) General function prediction only, (J) Translation, ribosomal structure and biogenesis in this study. Based on the related biochemical pathways, the KEGG database can represent another alternative functional annotation of genes. According to the KEGG classification, the largest amount of total annotations were involved in different metabolism pathways, among which the largest pathway was carbohydrate metabolism. (Additional file 1: Figure S3).

These results provide a valuable resource for investigating which genes involved in response to $M$. sanbourni infestation might play a key role in chrysanthemum molecular breeding.

Differential expression and gene functional classification We compared the DEGs among the multiple groups of samples. As shown in Fig. 2b, there was a large number of DEGs in B1 compared to B0, with 457 genes

Table 2 Annotation of unigenes in different database

\begin{tabular}{|c|c|c|}
\hline Database & No. of annotated unigenes & Percentage of annotated unigenes (\%) \\
\hline NR & 42,859 & 10.7 \\
\hline NT & 102,642 & 25.64 \\
\hline $\mathrm{KO}$ & 81,327 & 20.31 \\
\hline SwissProt & 163,850 & 40.93 \\
\hline PFAM & 161,161 & 40.26 \\
\hline $\mathrm{GO}$ & 161,161 & 40.26 \\
\hline KOG & 47,002 & 11.74 \\
\hline all Databases ${ }^{a}$ & 3747 & 0.93 \\
\hline at least one Database ${ }^{b}$ & 236,851 & 59.17 \\
\hline Total Unigenes & 400,234 & 100 \\
\hline
\end{tabular}

${ }^{a}$ Annotated in at least one of the above databases

${ }^{\mathrm{b}}$ Annotated in all of the above databases 


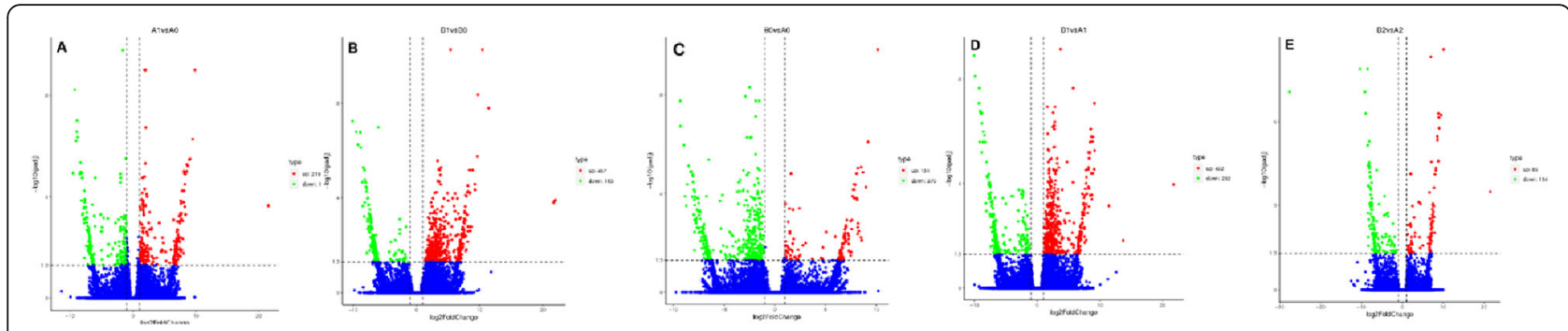

Fig. 2 Volcano plots of differentially expressed sequences in selfrooted grafted chrysanthemum and the grafted Artermisia-chrysanthemum. a The up-regulated or down-regulated genes in A1 compared to A0. b The up-regulated or down-regulated genes in B1 compared to B0. $\mathbf{c}$ The up-regulated or down-regulated genes in $\mathrm{B} 0$ compared to $\mathrm{A} 0$. $\mathbf{d}$ The up-regulated or down-regulated genes in $\mathrm{B} 1$ compared to A1. e The upregulated or down-regulated genes in B2 compared to B2. (The scattered points represent the genes, the blue dots represent the genes with no significant difference, the red dots represent the up-regulated genes with significant differences, and the green dots indicate the down-regulated genes with significant differences)

upregulated and 163 genes downregulated. However, there were 219 upregulated genes and 188 downregulated genes (Fig. 2a) among the DEGs in A1 compared to A0. From the overall expression of DEGs induced under aphid stress, the number of upregulated genes was higher than that of downregulated genes. The results indicated that most of the genes in chrysanthemum leaves were activated, and few genes were inhibited after stimulation. In total, the number of different genes in $\mathrm{Cm} /$ As was approximately twice that in $\mathrm{Cm} / \mathrm{Cm}$.

Furthermore, the results showed that there were 1337 DEGs, among which 680 were upregulated and 667 were downregulated, in the $\mathrm{Cm} / \mathrm{As}$ compared to the $\mathrm{Cm} /$ $\mathrm{Cm}$. Among them, there were 504 genes with different expression in $\mathrm{B} 0$ compared to $\mathrm{A} 0$, of which 134 genes were upregulated and 370 genes were downregulated (Fig. 2c); 620 genes were differentially expressed in B1 compared to A1, of which 457 genes were upregulated and 163 genes were downregulated (Fig. 2d); and 223 genes were differentially expressed in B2 compared to A2, with 89 upregulated genes and 134 downregulated genes (Fig. 2e). A total of 1337 DEGs were identified, as shown in Fig. 3. According to the GO classification (Fig. 3a), the largest amount of annotations was in the $\mathrm{BP}$ category, for which the top $3 \mathrm{GO}$ terms were singleorganism process, establishment of localization and regulation of biological; the second most abundantly annotated category was MF, for which the top 3 terms were transporter activity, ion transmembrane transporter and substrate-specific transmembrane; and the third most abundantly annotated category was $\mathrm{CC}$, for which the top term was MHC protein complex. The results of the KEGG pathway classification were shown in Fig. 3b, mainly including photosynthesis, trans-linolenic acid metabolism, pantothenic acid and CoA biosynthesis, plant hormone signal transduction pathways, phenylpropane
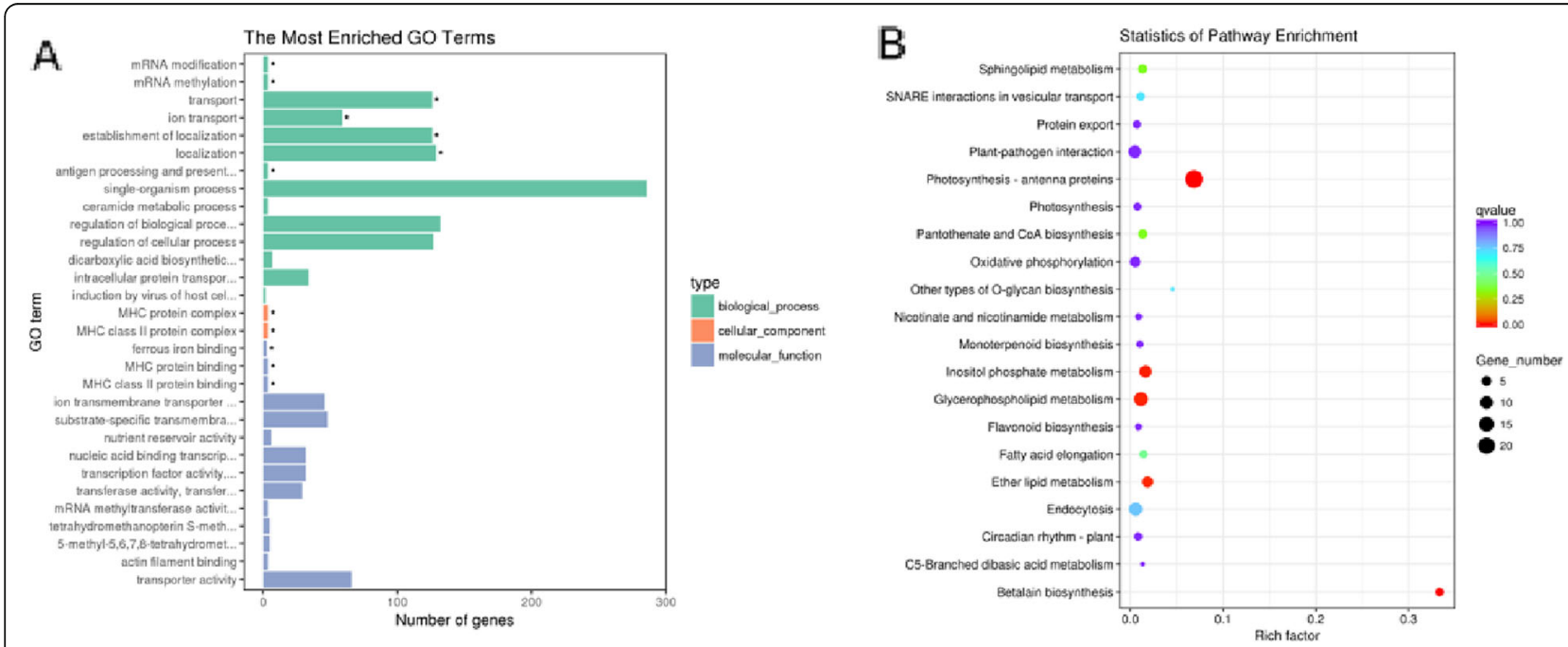

Fig. 3 Enrichment analysis of differently expressed genes between the selfrooted grafted chrysanthemum and grafted Artermisiachrysanthemum. a Functional enrichment categories of DEGs in Gene Ontology. ( ${ }^{*}$ indicates significant enrichment). b Scatterplot of enriched KEGG pathway of DEGs (Top 20) 
biosynthesis, betaine synthesis, monogamous biosynthesis, sucrose metabolism, flavonoid biosynthesis, and plantpathogen interactions. The results indicated that grafting chrysanthemum onto A. scoparia W. resulted in enhanced resistance to aphids, which was closely related to the regulation of metabolic pathways, secondary metabolic biosynthesis, immune response and signal transduction.

\section{Verification of DEGs using qRT-PCR}

To validate the results of Illumina RNA-Seq, fifteen genes from the library of the grafted and self-rooted seedlings after aphid infestation were chosen randomly for qRTPCR. For comparison, clustering heat maps between the RNA-Seq and qRT-PCR data were generated. As shown in Fig. 4, the qRT-PCR results revealed that the expression tendency of these genes showed significant similarity with the Illumina RNA-Seq data, suggesting the reproducibility and accuracy of the RNA-Seq results.

\section{Discussion}

\section{Genes related to sucrose metabolism}

Sucrose has a central position in plant metabolism as the first free sugar formed during photosynthesis $[23,24]$ and the major form of translocated sugar in the phloem [25]. Soluble sugars, such as sucrose, glucose and fructose, can be donors of carbon skeletons for secondary metabolism and signaling molecules that regulated the expression of genes encoding flavonoid biosynthesis enzymes [26]. Sucrose metabolism plays an important role in the defense against insect herbivores, such as aphids. In our study, as shown in Fig. 5a, the level of soluble sugar increased after $6 \mathrm{~h}$ of infestation and reached a maximum at $24 \mathrm{~h}$ in the $\mathrm{Cm} /$ As plants. At the same time point, a higher concentration of soluble sugar was observed in $\mathrm{Cm} / \mathrm{As}$ than in $\mathrm{Cm} / \mathrm{Cm}$.

The multiple roles of plant sucrose transporters, especially the central role of sucrose loading into the phloem, suggest that sucrose transport is strongly regulated by biotic stresses [27-29]. In the present study, nine genes involved in the sucrose metabolism pathway were differentially expressed between $\mathrm{Cm} / \mathrm{As}$ and $\mathrm{Cm} / \mathrm{Cm}$. As shown in Fig. 5b, three INV genes (Cluster-21, 353.120200, Cluster-21,353.176307 and Cluster-21, 353.133225), one PYG gene (Cluster-21,353.277981) and one PGM gene (Cluster-21,353.147957) were strongly upregulated in $\mathrm{Cm} / \mathrm{As}$ (B1) compared to $\mathrm{Cm} / \mathrm{Cm}$ (A1) at $6 \mathrm{~h}$, and these genes have been shown to be involved in glucose synthesis (Fig. 5c). In addition, there were four downregulated genes in B1 compared with A1, including two OTS genes (Cluster-21,353.199573 and Cluster-21,353.175120) and two BPGM genes (Cluster-21,353.178805 and Cluster-21,353.224391), which have been shown to be involved in glucolysis (Fig. 5c). The results suggested that grafting chrysanthemum onto A. scoparia W. accelerated the synthesis of soluble sugars, which increased the carbon metabolism burden of aphids and thus prevented aphids from feeding on the leaves. The details of these genes are shown in Additional file 2: Table S1. These genes may play an important role in promoting the synthesis of soluble sugars at the early stage in response to M. sanbourni infestation in the $\mathrm{Cm} /$ As seedlings.

\section{Genes related to secondary metabolism}

Secondary metabolites, for example, flavonoids, terpenes, phenolics and alkaloids, have antixenotic or antibiotic properties and thus function in the defense against insect herbivores, such as aphids [22]. Among secondary metabolites, flavonoids are responsible for many key functions, which are critical for plant survival [30]. Flavonoids are catalyzed by amount of enzymes, such as PAL, which has been studied in plant responses to biotic and abiotic stresses [31]. In the present study (Fig. 6c), the activity of PAL in Cm / As was significantly increased by aphid infestation and higher than that in $\mathrm{Cm} / \mathrm{Cm}$, which promoted the accumulation of flavonoids. Studies

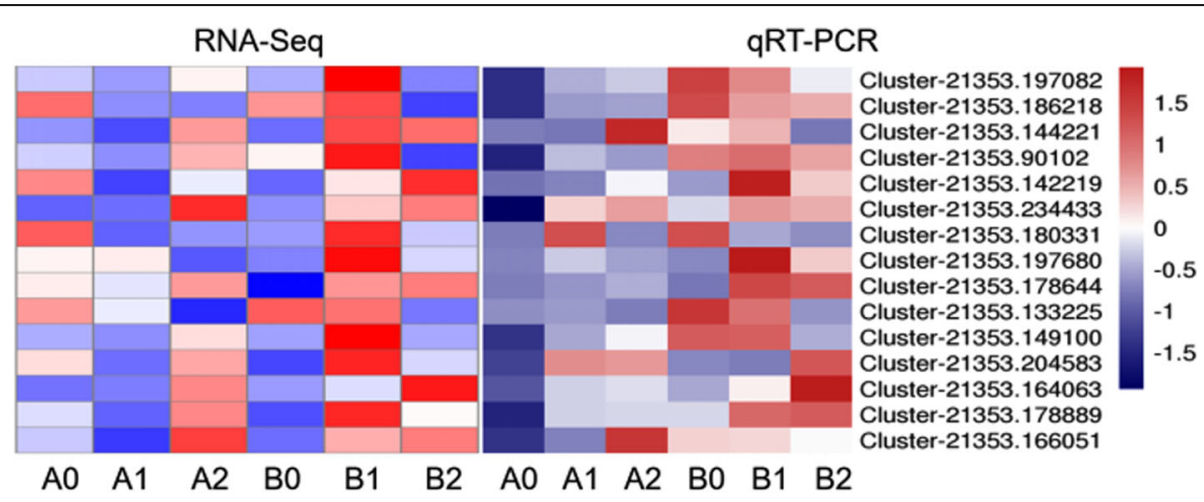

Fig. 4 Comparisons of the expression changes of selected genes during aphid stress in qRT-PCR and RNA-Seq analysis were used in heat map analysis. Different colors indicate different levels of genes expression: from red to green, the value ranges from large to small 


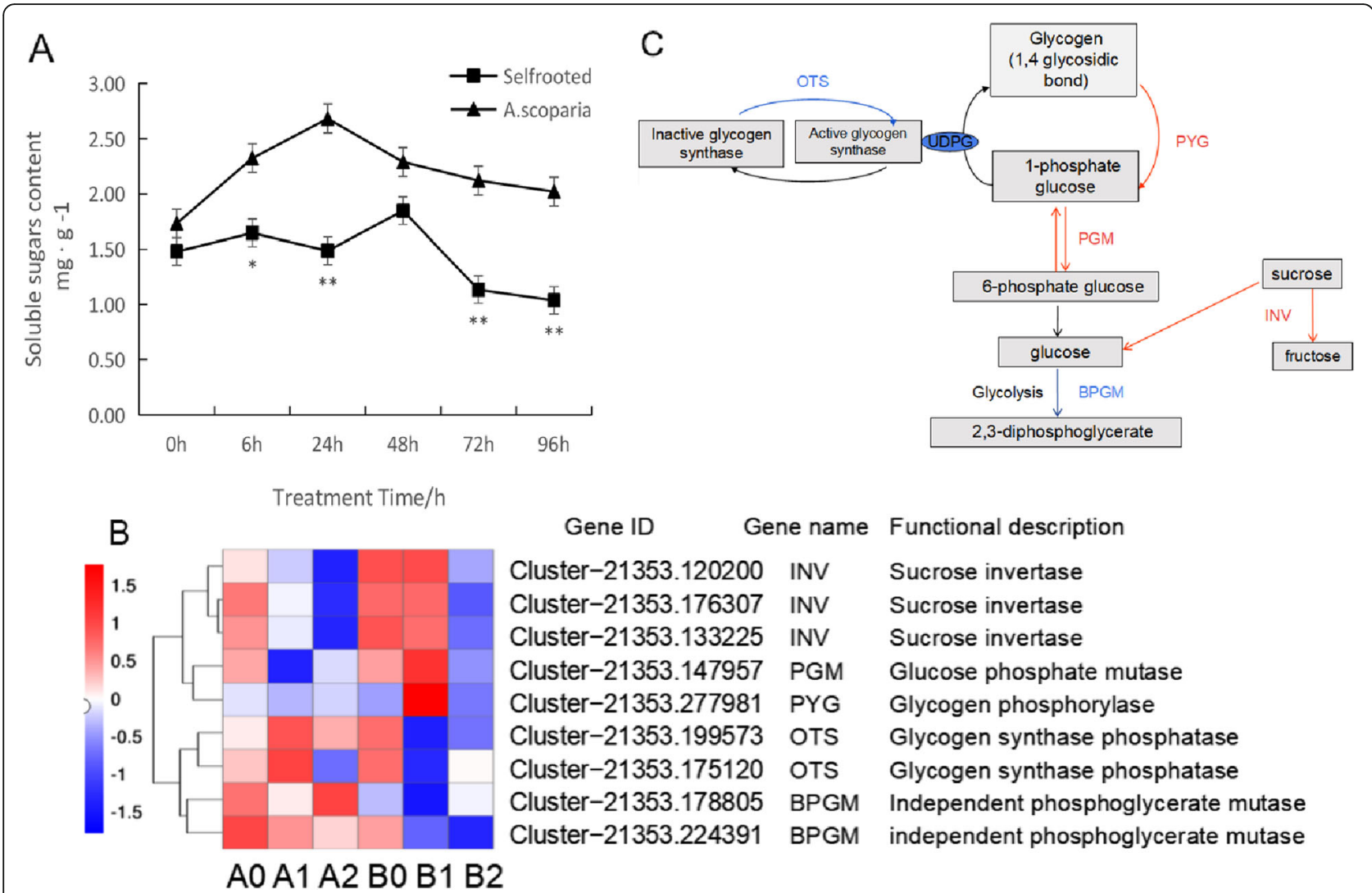

Fig. 5 Sucrose metabolism related genes. a Effect of aphid stress on content of total sugars (* and $* *$ indicate significant differences (respectively, $P \leq 0.05$ and $P \leq 0.01$ ). b Heat map of the DEGs involved in sucrose metabolism. $\mathbf{c}$ The metabolic pathway analysis of unigenes involved in sucrose metabolism (Red and blue lines indicate up-regulated and down-regulated genes in $\mathrm{Cm} / \mathrm{As}$ compared to $\mathrm{Cm} / \mathrm{Cm}$, respectively)

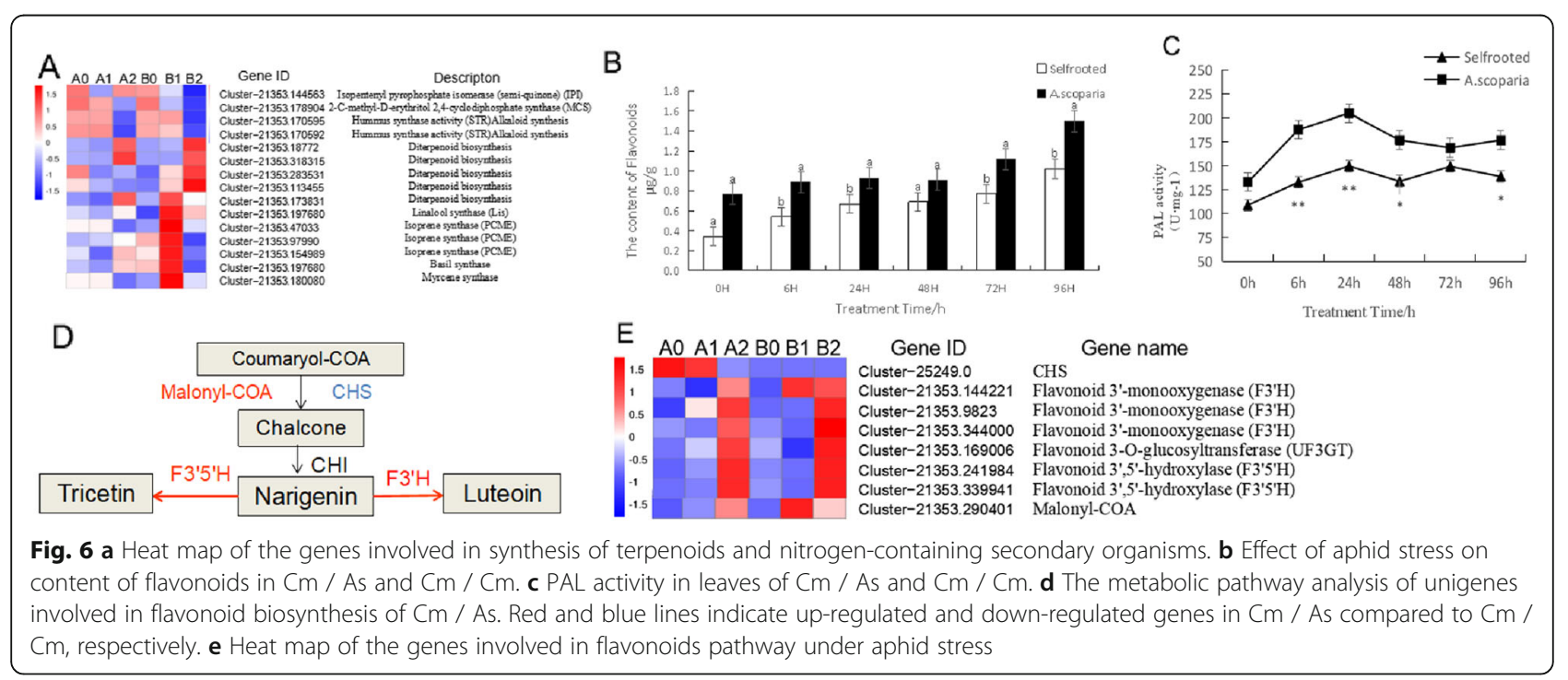


on insect-plant interactions have revealed important contributions of flavonoids [32]. In Vigna [33], there was a positive relationship between resistance or susceptibility properties against aphids and the flavonoid glycoside content. The content of flavonoids in susceptible lines was lower than that in resistant lines [34]. In the present study, after $A$. sanbourni infestation, flavonoid accumulation was detected in the leaves of $\mathrm{Cm} / \mathrm{As}$ and $\mathrm{Cm} / \mathrm{Cm}$. The level of flavonoids increased after $6 \mathrm{~h}$ of infestation, and a higher concentration of flavonoid was observed in $\mathrm{Cm} /$ As than in $\mathrm{Cm} / \mathrm{Cm}$ (Fig. 6b). Additionally, genes related to flavonoid synthesis were also identified. Eight genes were differentially expressed between $\mathrm{Cm} / \mathrm{As}$ and $\mathrm{Cm} /$ $\mathrm{Cm}$ (Fig. 6d-e), including one CHS gene (Cluster-25, 249.0), which was downregulated in B1 compared to B0, and one malonyl-CoA gene (Cluster-21,353.290401), which was strongly upregulated in B1 compared to A1 and may play an important role in $\mathrm{Cm} / \mathrm{As}$ defense towards aphid feeding at the early stage of infestation. In addition, three flavonoid 3'-monooxygenase $\left(F 3^{\prime} H\right)$ genes (Cluster-21,353.144221, Cluster-21,353.9823 and Cluster21,353. 344,000), two flavonoid 3'5'-hydroxylase $\left(F 3^{\prime}{ }^{\prime} H\right)$ genes (Cluster-21,353.241984 and Cluster-21,353. 339, 941) and one flavonoid 3-O-glucosyltransferase gene (Cluster-21,353.169006) were strongly upregulated in B2 compared to A2, which could play an important role in $\mathrm{Cm} / \mathrm{As}$ defense towards aphid feeding in the later stage of infestation (Fig. 6d).

In addition, among secondary metabolites, alkaloids act as a defense against insects and other herbivores $[35,36]$. For example, the reduced alkaloid content in sweet lupins led to a high susceptibility to insect herbivores, e.g., aphids [37-39]. In this study, only two alkaloid synthesis-related genes, STR genes (Cluster-21,353.170595 and Cluster-21, 353.170592), were detected in $\mathrm{Cm} / \mathrm{As}$ and $\mathrm{Cm} / \mathrm{Cm}$, both of which were downregulated at $96 \mathrm{~h}$ after aphid infestation.

Plants produce a vast array of volatiles that mediate their interaction with the environment and that consist of terpenoids and isoprenoids, which are synthesized through the condensation of $C 5$ isoprene units. Monoterpenes and sesquiterpenes represent the $\mathrm{C} 10$ and $\mathrm{C} 15$ terpene classes, respectively. These compound classes have typical characteristics, such as volatility, flavor/ aroma, and toxicity, and hence play important roles in plant defense and pollinator attraction [40]. A previous study found that the increased content of monoterpenoids and sesquiterpenoids in the leaves of the hybrid between chrysanthemum and Artemisia vulgaris enhanced the resistance of the plant to aphids [9]. In the present study, we obtained several DEGs related to terpenoid synthesis (Fig. 6a). There were three genes related to monoterpene synthesis, one basil synthase gene (Cluster-21,353.197680), one myrcene synthase gene
(Cluster-21,353.180080) and three isoprenoid genes (Cluster-21,353.97990, Cluster-21,353.154989 and Cluster-21,353.47033). All of these genes were strongly upregulated in $\mathrm{B} 1$ compared to $\mathrm{A} 1$, indicating their potential roles in the defense responses against aphids in the early stage after grafting on A. scoparia W. Furthermore, five genes involved in diterpenoid biosynthesis, including one gene (Cluster-21,353.173831), were strongly upregulated in B1 compared to A1, and four genes (Cluster-21,353.18772, Cluster-21,353.318315, Cluster21,353.283531 and Cluster-21,353.113455) were strongly upregulated in B2 compared to A2 and may play important roles in responding to aphids in the later stage of infestation.

The details of these genes discussed above are shown in Additional file 3: Table S2, which illustrates the involvement of secondary metabolites during aphid herbivory in $\mathrm{Cm} / \mathrm{As}$ and $\mathrm{Cm} / \mathrm{Cm}$ leaves, indicating that using the A. scoparia W. rootstock could alleviate aphid stress in chrysanthemums by altering these gene profiles, which play potential roles in defense responses to aphids.

\section{Plant hormone signaling pathway involved in plant-aphid interaction}

JA, SA and ET are three major phytohormones involved in the regulation of signaling networks related to aphidinfestation defense responses. As shown in Fig. 7a, hormone transduction pathway-related genes were expressed at different time points between $\mathrm{Cm} / \mathrm{As}$ and $\mathrm{Cm} / \mathrm{Cm}$. A total of 21 DEGs were involved in several plant hormone signal transduction pathways, including cytokinins (CKs), ET, JA and SA, in this study. The details of these genes discussed above are shown in Additional file 4: Table S3.

The JA pathway and SA pathway are two main pathways involved in plant-induced defense [41]. Phytohormonal crosstalk between JA- and SA-mediated signaling pathways is thought to underlie plant-mediated interactions among multiple insect species and the behavioral responses of parasitoids and predators [10, 42, 43]. The activation of SA signaling in response to aphid feeding $[18,44,45]$ may suppress JA-dependent indirect defense responses. In our study (Fig. 7a), one LOX gene, which is a key enzyme in JA synthesis, was downregulated in B1 compared to B0, whereas the $S A B P$ genes, which are key enzymes in SA synthesis, were strongly upregulated in $\mathrm{B} 1$ compared to B0.

Exogenous SA treatment can enhance plant resistance to pathogenic bacteria and induce the expression of disease-related genes at the same time [46, 47]. SABP2 catalyzes the conversion of MeSA into SA, which is essential for inducing tobacco systemic acquired resistance (SAR) [48]. In this study, three SABP2 genes (Cluster-21, 


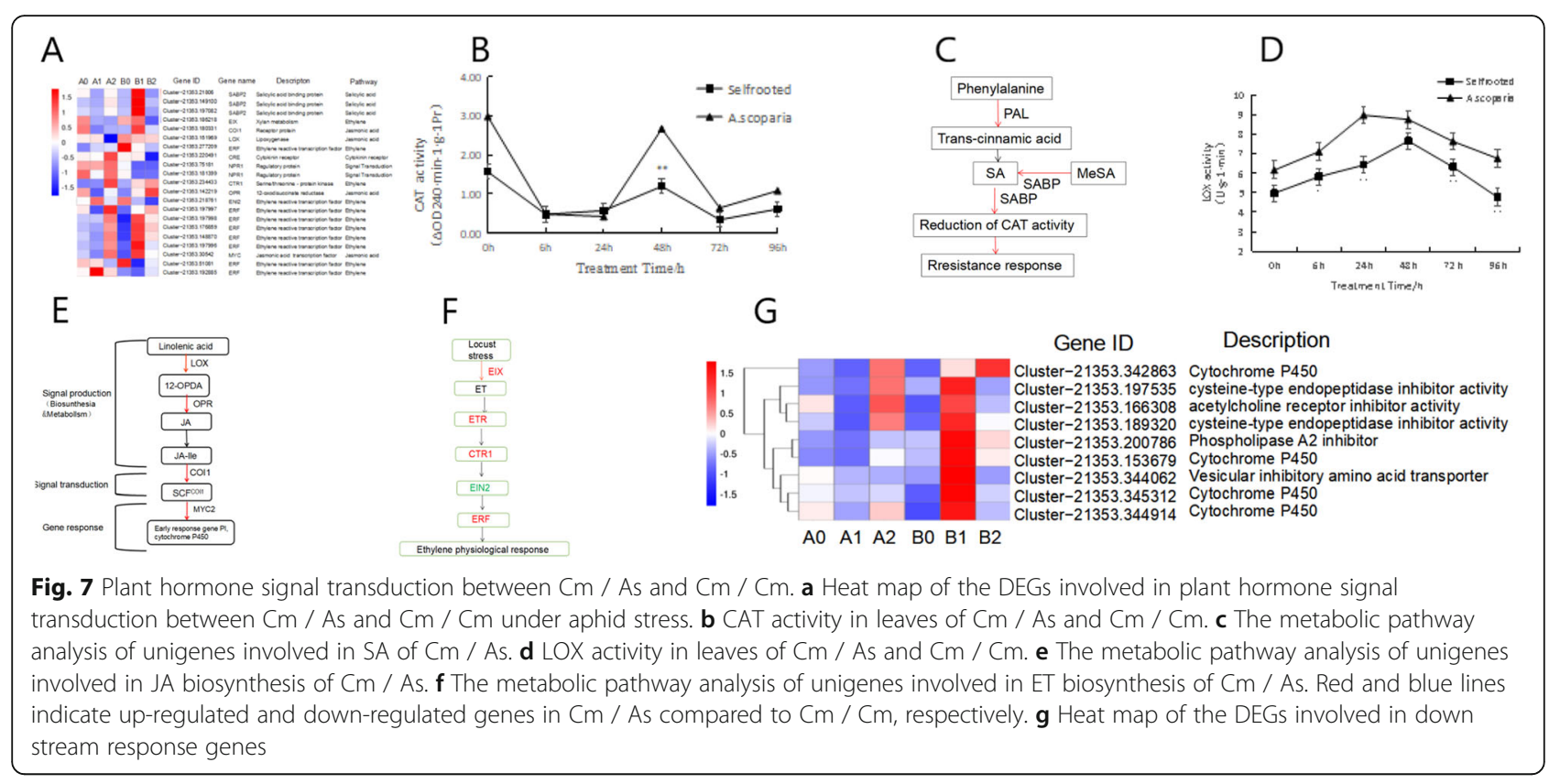

353.21806, Cluster-21,353.149100 and Cluster-21, 353.197082) were upregulated by aphid infestation in B1 compared to A1 in the early stage. In addition, within 6 $\mathrm{h}$ of infestation with aphids, the CAT activity in the $\mathrm{Cm}$ / As and $\mathrm{Cm} / \mathrm{Cm}$ plants decreased rapidly by 69.5 and $83.7 \%$, respectively (Fig. $7 \mathrm{~b}$ ). This result might be due to the change in the conformation of CAT, which binds to the SA-binding protein (SABP1) [49], inhibiting the activity of CAT and activating the expression of disease course-related protein genes. We suggest that grafting chrysanthemum onto A. scoparia W. inhibited the activity of CAT through the upregulation of $S A B P 2$ genes after aphid infestation (Fig. 7c), and then the selffeedback mechanism was initiated, which amplified the signal transduction in the cell and ultimately induced the expression of the disease-related protein genes (Fig. 7g). Furthermore, in the SA-mediated SAR reaction of Arabidopsis, NPR1 is a crucial regulatory protein that impacts the SAR pathway downstream of the SA signaling pathway. During SAR, NPR1 induces PR gene expression, and even after induction by SA, BTH or INA, NPR1 expression levels increase [50, 51]. However, in this study (Fig. 7a), two NPR1 genes were downregulated in B1VSA1, suggesting that the NPR1 gene had different regulatory mechanisms on aphid stress after grafting onto A. scoparia W.

JA affects not only the growth of many plants but also the resistance of plants to pathogen infection. LOX and oxo-phytodienoic reductase (OPR) are not only key enzymes for JA synthesis but also important substances that induce defense mechanisms in plants [52-54]. As the receptor in the JA signaling pathway, COI1 (COR-insensitive1) can interact with SKP1 (S-phase kinase- associated protein1) [55]. LOX genes were significantly upregulated by $M$. persicae feeding on $A$. thaliana leaves [21], M. nicotianae feeding on Nicotiana attenuata leaves [56], and M. euphorbiae feeding on tomato leaf tissues [57]. In our study (Fig. 7e), the overall expression level of one LOX gene (Cluster-21,353.151969) in the $\mathrm{Cm} /$ As plants was higher than that in the $\mathrm{Cm} / \mathrm{Cm}$ plants at the same time point. Additionally, the activity of LOX (Fig. 7d) in Cm / As was significantly increased by aphid infestation and higher than that in $\mathrm{Cm} / \mathrm{Cm}$, which promoted the accumulation of JA. Compared with A2, B2 exhibited one OPR gene (Cluster-21,353.142219) that was strongly upregulated. In addition, one COI1 gene (Cluster-21,353.180331) and one MYC gene (Cluster-21,353.197996) were strongly upregulated in B1 compared to A1 and responded rapidly to aphid stress in the early stage of infestation. In addition, protease inhibitors (PIs) are widely found in organisms, regulate many important biological activities in plants and have a protective effect against insects [58]. These genes above all activated the expression of cytochrome P450 genes and protease inhibitor genes, which were downstream response genes (Fig. $7 \mathrm{~g}$ ) responding to aphid stress. The details of these genes discussed above are shown in Additional file 5: Table S4. In this study, four cytochrome P450 genes (Cluster-21,353.342863, Cluster-21,353.153679, Cluster-21,353.345312 and Cluster-21,353.344914) were upregulated by aphid infestation in B1 compared to A1. Protease inhibitors were divided into four categories, serine protease inhibitors, metal carboxypeptidase protease inhibitors, cysteine protease inhibitors and aspartic acid protease inhibitors, according to the active sites of the active enzymes [59]. In our study, two cysteine protease inhibitor genes 
(Cluster-21,353.197535 and Cluster-21,353.189320) and one phospholipase A2 inhibitor gene (Cluster-21,353.200786) were significantly upregulated by aphid infestation in B1 compared to A1. As important enzymes, the acetylcholine receptor inhibitor gene and the phospholipase A2 inhibitor gene can inhibit the nerve conduction of insects, which may play an important role in responding to aphids in the early stage of infestation after grafting onto A. scoparia W.

Some studies have proven that aphid infestation markedly increases the production of ET in the leaves of plants [60-62]. Ethylene-inducing xylanase (EIX) induces ET production and is an effective elicitor of plant defense responses in specific cultivated species of Nicotiana tabacum and Lycopersicon esculentum. In the present study, one EIX gene (Cluster-21,353.186218) was strongly upregulated in $\mathrm{B} 1$ compared to $\mathrm{A} 1$, which may stimulate the accumulation of ET (Fig. 7f). CTR1 is a negative regulatory component downstream of the ET receptor and the first cloned gene in the ET signal pathway $[63,64]$. In this study (Fig. 7a), one CTR gene (Cluster-21,353.234433) was upregulated in $\mathrm{B} 1$ compared to A1 at an early time point after aphid infestation. Research shows that EIN2 has important effects in the ET signal pathway, and the loss of EIN2 gene function leaves the plant completely insensitive to ET [65]. In this study (Fig. 7a), one EIN2 transcription factor gene was downregulated in B1 compared to B0, but it was highly expressed in A1. ET-responsive factor $(E R F)$ encodes a transcriptional activator to promote several downstream ET-responsive genes. Additionally, MYC and ERF transcription factors, participate in the ET and JA signaling pathways and activate defense-related genes. In our study, nine $E R F$ genes were involved; among them, four genes (Cluster-21,353.197997, Cluster-21,353.197998, Cluster-21,353.176859 and Cluster-21,353.148870) were strongly upregulated in B1 compared with A1 (Fig. 7a).

These DEGs were identified in the comparison of $\mathrm{Cm}$ / As and $\mathrm{Cm} / \mathrm{Cm}$, as discussed above, which illustrates the involvement of the plant hormone signaling pathway during aphid herbivory, indicating their potential roles and the complex connections in the defense responses against aphids after grafting chrysanthemum onto A. scoparia W.

\section{Plant-pathogen interaction}

Two layers of plant immunity are well defined: patterntriggered immunity (PTI) and effector-triggered immunity (ETI) [66]. As the first line of the innate immune response, PTI is triggered by the perception of herbivoreassociated molecular patterns (HAMPs) in the case of herbivory and microbe-associated molecular patterns (MAMPs) or pathogen-associated molecular patterns (PAMPs) by cognate plasma membrane-localized pattern recognition receptors (PRRs) in the case of microbial infection [67]. The downstream immune signaling pathways are activated by different PRRs, including the receptor of kinases and the activation of various kinases, such as mitogen-activated protein kinase (MAPK) and calciumdependent protein kinase (CDPK) [68]. In this study, four genes in the MAPK signaling pathway were recognized (Fig. 8): one $R O B H$ gene (Cluster-21,353.196945) and one $M A P K$ gene (Cluster-21,353.172651), which were upregulated in B1 compared to A1, and one WRKY2209 gene (Cluster-21,353.216549) and one ROBH gene (Cluster-21, 353.177651), which were upregulated in B2 compared to A2.

$\mathrm{Ca}^{2+}$ regulates many important physiological processes. Transcriptome and metabolome changes in Arabidopsis were surveyed at $6 \mathrm{~h}, 12 \mathrm{~h}, 24 \mathrm{~h}$ and $48 \mathrm{~h}$ after $B$. brassicae infestation, revealing that reactive calcium is involved in early signaling [69]. Plant defenses against phloem-feeding insects involve multiple signaling cascades, and molecular genetic studies on the model plant $A$. thaliana have demonstrated that leucine-rich repeat $(L R R)$ family receptor-like kinases and calcium signaling proteins are partially activated by phloem feeding [70]. MHCII molecules can mediate the transmission of reverse signals and influence and regulate many physiological processes in immune cells [71]. Studies have shown that CDPK2 and MHCII can regulate each other in two major antigen presenting cells [60]. In the present study (Fig. 8), four CDPK genes (Cluster-21,353.147746, Cluster-21,353.90102, Cluster-21,353.147746 and Cluster-21,353.90102) and three MHCII genes (Cluster-21,353.251721, Cluster21,353.196511 and Cluster-21,353.177618) were specifically upregulated in $\mathrm{B} 1$ compared to $\mathrm{A} 1$, which may play an important role in the early stage of responding to M. sanbourni infestation in $\mathrm{Cm} /$ As seedlings.

Two cloned aphid resistance genes, Mi-1.2, confer resistance to the potato aphid, Macrosiphum euphorbiae (Thomas) [72, 73], and Vat mediates resistance to the cotton aphid Aphis gossypii Glover [74, 75], all of which belong to the NBS-LRR family. Similarly, we found four such DEGs (Cluster-21,353.336850, Cluster-21,353.79718, Cluster-21,353.149283 and Cluster-21,353.102248) between the $\mathrm{Cm} / \mathrm{Cm}$ plants and the $\mathrm{Cm} / \mathrm{As}$ plants, but these DEGs require further cloning and functional identification to confirm the presence of the NBS-LRR region.

Furthermore, in our study (Fig. 8), there were many DEGs related to tyrosine protein kinases and serine/threonine protein kinases in the interaction between the plants of the $\mathrm{Cm} / \mathrm{Cm}$ and the $\mathrm{Cm} /$ As. Eight PAK genes and six PTK genes were specifically upregulated in B1 compared to A1. These protein kinase genes may be closely related to grafting to improve the aphid resistance of C. morifolium $\mathrm{T}$. (The details of these genes discussed above are shown in Additional file 6: Table S5). 


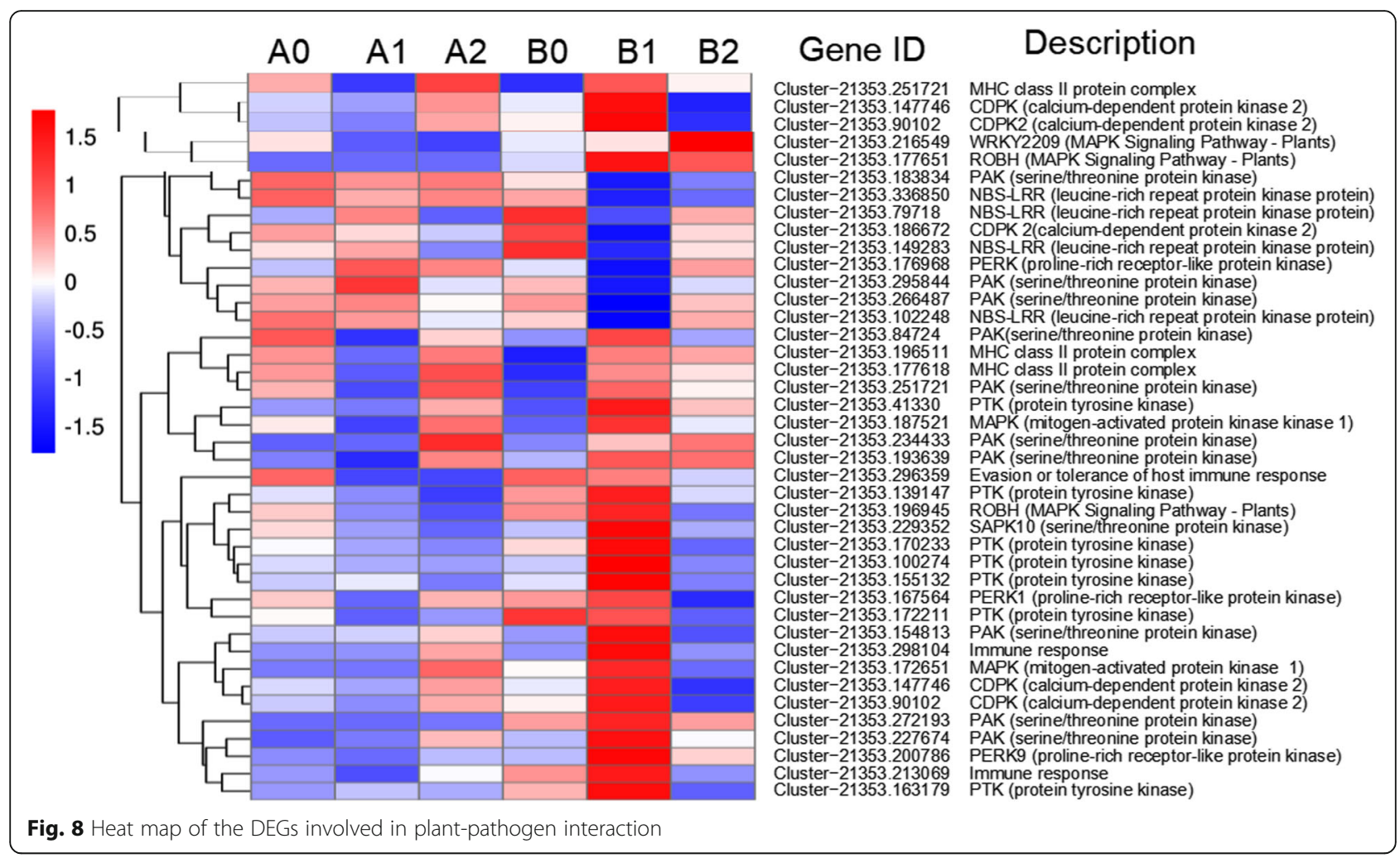

\section{Conclusions}

This study showed that the number of aphids was significantly lower in Cm / As than in Cm / Cm $10 \mathrm{~d}$ after aphid infestation. The results indicated that grafting chrysanthemum onto A. scoparia W. resulted in enhanced resistance to aphids. In addition, the content of soluble sugars and the accumulation of flavonoids in $\mathrm{Cm} / \mathrm{As}$ were higher than those of $\mathrm{Cm} / \mathrm{Cm}$ at the same time point under aphid stress. Transcriptome results showed that grafting onto A. scoparia W. affected aphid-responsive and defense-related gene expression after feeding, mainly in the processes of sucrose metabolism, plant hormone signaling, secondary metabolism and plant-pathogen interaction. Intercommunication typically occurred between the different defense pathways to which these genes belonged, thereby providing the $\mathrm{Cm} /$ As seedlings the ability to integrate environmental, developmental and defense-related signals and to finetune their defense responses to aphids.

\section{Methods}

\section{Study sites and sampling Plant materials}

The cultivar Chrysanthemum morifolium T. 'Hangbaiju' is a national geographical indication product in Tongxiang, Zhejiang Province, China. The material has been deposited in Chinese Virtual Herbarium, and the deposition number is JJF00030415. The materials were collected in
2010 in Tongxiang, authenticated by Professor Chengshu Zheng (Shandong Agricultural University) and then preserved in the Chrysanthemum Germplasm Resource Preservation Center at Shandong Agricultural University. In the present study, 'Hangbaiju' was obtained from the Chrysanthemum Germplasm Resource Preservation Center, and plants were subsequently verified by Shandong Agricultural University scientists based on Cheng-shu Zheng. The seeds of Artemisia scoparia W. was obtained from the Chrysanthemum Germplasm Resource Preservation Center which were sown on March 10th in plastic pots $(19 \mathrm{~cm}$ in diameter $\times 17 \mathrm{~cm}$ in depth) filled with a 2 : 1:1 (v/v/v) mixture of garden soil, peat and vermiculite. On May 1st, healthy A. scoparia W. and chrysanthemum plants $30 \mathrm{~cm}$ in height and with a 6-mm stem diameter were used as rootstocks, and apical shoots with a length of $14 \sim 16 \mathrm{~cm}$ and a stem diameter of $4 \mathrm{~mm}$ from healthy chrysanthemum were used as scions. Insert grafting was performed as described by Lee (Lee 1994). On July 9th, morphologically uniform $\mathrm{Cm} / \mathrm{Cm}$ and $\mathrm{Cm} /$ As plants were selected for the aphid infestation treatment. The plants were arranged in a fully randomized manner, and the experiment was repeated three times, with each replicate consisting of 15 plants.

\section{Aphid infestation}

Aphids (M. sanbourni) were collected from field-grown chrysanthemum plants, and second-instar nymphs were 
fostered and used to inoculate the plants. The third fully expanded leaves from the tip of the stem of the $\mathrm{Cm} /$ $\mathrm{Cm}$ and $\mathrm{Cm} /$ As plants were infested with twenty aphids ( $4 \mathrm{~h}$ of starvation) transferred by a soft brush. Twenty plants per treatment were repeated three times. The infested plants were caged with a transparent ventilated plastic net. Aphids were counted $1 \mathrm{~d}, 3 \mathrm{~d}, 5 \mathrm{~d}, 7 \mathrm{~d}$, $9 \mathrm{~d}$ and $10 \mathrm{~d}$ after aphid inoculation.

The third fully expanded leaves of seedlings for each treatment were harvested at $0 \mathrm{~h}, 6 \mathrm{~h}$, and $96 \mathrm{~h}$. Before harvest, aphids were removed with a soft brush, which enabled the aphids to be removed from the leaves by flushing the plants with deionized water. Harvested materials were immediately frozen in liquid nitrogen and stored at $-80^{\circ} \mathrm{C}$ for the following experiments. The samples collected at defined time points of each treatment were pooled for RNA-Seq.

\section{RNA extraction and transcriptome sequencing}

The RNA isolation was performed using the CTAB method according to Chang et al. [76]. A total amount of $1.5 \mu \mathrm{g}$ RNA per sample was used as input material for the RNA sample preparations. Sequencing libraries were generated using the NEB Next ${ }^{\bullet}$ Ultra $^{\text {Tax }}$ RNA Library Prep Kit for Illumina. RNA from three leaves of the same plant were pooled equimolarly and used as a single sample for the following transcriptome sequencing. Finally, these libraries were sequenced at Novogene Biological Information Technology Co., LTD. (Tianjin, China) using the Illumina Hiseq 4000 platform (San Diego, CA, USA). The transcriptome of each treatment was analyzed at three time points $(0 \mathrm{~h}, 6 \mathrm{~h}$ and $96 \mathrm{~h})$ with three biological replicates for each time point. In total, eighteen samples were used for transcriptome sequencing. According to three time points, the samples were: A0, A1, A2, B0, B1 and B2 (Table 3).

\section{Transcriptome assembly and gene functional annotation} Transcriptome assembly was finished based on these high-quality reads of all samples by using Trinity software [69]. Raw reads were processed to remove reads which containing adaptors, reads of low quality (more than $50 \%$ bases with small Qphred $\leq 5$ ), or with more than $10 \%$ ambiguous bases $(\mathrm{N})$ to get clean reads for the

Table 3 Samples for the transcriptome sequencing

\begin{tabular}{lll}
\hline Rootstock & Sample & Time of inoculation \\
\hline Selfrooted & A0 & $0 \mathrm{~h}$ \\
& A1 & $6 \mathrm{~h}$ \\
A.scoparia & A2 & $96 \mathrm{~h}$ \\
& B0 & $0 \mathrm{~h}$ \\
& B1 & $6 \mathrm{~h}$ \\
& B2 & $96 \mathrm{~h}$ \\
\hline
\end{tabular}

following analysis. The longest transcript from all libraries was selected as the non-redundant unigene of this study.

To obtain gene functional annotations of Chrysanthemum morifolium T. 'Hangbaiju' transcriptome, the BLAST searches were performed using the sequences of the resulting unigenes based on the following databases: NCBI nonredundant nucleotide sequences $(\mathrm{Nt}), \mathrm{NCBI}$ nonredundant protein sequences (Nr), Swiss-Prot, euKaryotic Ortholog Groups (KOG), GO (Gene Ontology), KEGG (Kyoto Encyclopedia of Genes and Genomes). The E-value threshold was set to $1 \mathrm{E}-3$ in the alignments to KOG. For the alignments to Swiss-Prot and $\mathrm{Nt}$, the E-value threshold was 1E-5. KEGG Automatic Annotation Server (http://www.genome.jp/kegg/ kaas/) was used for the KEGG annotations [77]. The GO annotations were performed with Blast $2 \mathrm{GO}$ v2.5 [78] which according to the $\mathrm{Nr}$ and Pfam annotations. Pathway assignments were also mapped based on the KEGG database.

\section{Differential expression analysis}

Fragments Per Kilobase per Million fragments (FPKM) method [79] was used to numerate the unigene expression level. FPKM values were used to demonstrate the gene expression levels in different samples. To examine the effects of the different aphid infestation times on the gene expression patterns of leaves in the $\mathrm{Cm} / \mathrm{Cm}$ and $\mathrm{Cm} /$ As plants, the density distributions of FPKM values were compared among different aphid infestation time groups in this study. DEGs were determined based on an absolute value of fold change $\geq 2$ and a threshold of q-value $\leq 0.05$. Here, the q-value was adopted to adjust the $P$-values in multiple hypothesis tests [80]. In this study, hierarchical clustering was used to demonstrate the differential gene expression patterns between different aphid stress time points in the $\mathrm{Cm} / \mathrm{Cm}$ and $\mathrm{Cm} /$ As plants. According to the functional annotations of the resulting unigenes, putative functions of the differentially expressed genes (DEGs) were deduced to discover the candidate genes for aphid infestation in chrysanthemum.

\section{Validation of RNA-Seq data by qRT-PCR}

The expression of 15 DEGs in chrysanthemum was analyzed by qRT-PCR with three replicates to verify the RNA-Seq data. Prime Script ${ }^{\mathrm{m}} \mathrm{RT}$ reagent qRT-PCR Kit with gDNA Eraser (Takara, Dalian, China), cDNA was synthesized, and genomic DNA was removed from total RNAs. The PCR mixture included $12.5 \mu \mathrm{L} \mathrm{SYBR}^{\circ}$ Premix Ex Taq ${ }^{\mathrm{TM}} \mathrm{II}, 9.50 \mu \mathrm{L} \mathrm{ddH}_{2} \mathrm{O}, 1 \mu \mathrm{L}$ of each gene-specific primer $(10 \mu \mathrm{M})$ and $1 \mu \mathrm{L}$ cDNA template. The qRT-PCR assays were performed with the following program: $94{ }^{\circ} \mathrm{C}$ for $3 \mathrm{~min} ; 40$ cycles of $94{ }^{\circ} \mathrm{C}$ for $20 \mathrm{~s}, 57^{\circ} \mathrm{C}$ for $20 \mathrm{~s}$ and $72{ }^{\circ} \mathrm{C}$ for $30 \mathrm{~s}$. Relative expression values of genes were calculated by the formula of 2 (38-value of $\mathrm{Cp}$ ) 
[81]. Cp indicates the intersection point and the cycles during which the signals were higher than the threshold. If the value of $\mathrm{Cp}$ exceeded 38, the data had high uncertainty. The relative expression value of actin was used as an internal control. Three technical replicates were performed for all fifteen selected genes.

\section{Determination of physiological indexes of chrysanthemum during aphid infestation}

Leaves of seedlings under aphid stress were harvested at $0 \mathrm{~h}, 6 \mathrm{~h}, 24 \mathrm{~h}, 48 \mathrm{~h}, 72 \mathrm{~h}$, and $96 \mathrm{~h}$ to determine the physiological indexes. The activities of phenylalanine ammonia lyase (PAL) and catalase (CAT) were determined by the "Plant Physiology Experiment Instruction" [82], and the content of soluble sugar was determined by the "Plant Physiology Experimental Technique" [83]. The flavonoid content was determined according to Jia [84]. The activity of lipoxygenase (LOX) was measured as described by Zhang et al. [85]. Each determination included three biological and technical replicates.

\section{Statistical analyses}

Statistical analyses of aphid numbers, enzymes and metabolites were performed by ANOVA (SAS Institute, Cary, NC, USA) using SPSS v. 21.0 (SPSS Inc., Chicago, IL, USA), and the determinations were expressed as the means \pm standard error (SE) from a minimum of three replicates. Differences between means were compared using Tukey's multiple range tests at $P<0.05$ or $P<0.01$.

\section{Supplementary information}

Supplementary information accompanies this paper at https://doi.org/10. 1186/s12864-019-6158-3.

Additional file 1: Figure S1. Composition of raw reads in the eighteen RNA libraries. Figure S2. Unigene Transcript length distribution. Figure S3. Functional classification and pathway assignment of DEGs by GO and KEGG.

Additional file 2: Table S1. Genes involved in sucrose metabolism to aphid infestation responses.

Additional file 3: Table S2. Genes involved in secondary metabolism to aphid infestation responses.

Additional file 4: Table S3. Genes involved in Plant hormone signaling pathway to aphid infestation responses.

Additional file 5: Table S4. Genes involved in down stream responses. Additional file 6: Table S5. Genes involved in Plant-pathogen interaction to aphid infestation responses.

\section{Abbreviations}

BP: Biological process; CC: Cellular component; cDNA: Complementary DNA; CHS: Chalcone synthase gene; Ct: Threshold cycle; DEGs: Differentially expressed genes; FPKM: Fragments Per Kilobase per Million fragments; GO: Gene Ontology; KEGG: Kyoto Encyclopedia of Genes and Genomes; KO: KEGG ortholog database; KOG/COG: Clusters of orthologous groups of proteins; MF: Molecular function; NR: NCBI non-redundant protein sequences; NT: NCBI non-redundant nucleotide sequences; Pfam: Protein family; qRTPCR: Quantitative real-time-polymerase chain reaction; RNA-Seq: Highthroughput RNA-sequencing; Swiss-Prot: A manually annotated and reviewed protein sequence database

\section{Acknowledgments}

Not applicable.

\section{Authors' contributions}

XS conceived the idea and supervised the project. FL and XZ participated in the design of the study and in interpreting the data, and manuscript preparation. XZ performed the experiments and the data analysis, and drafted the manuscript. SZ, JY and JF, contributed analysis tools and participated in the data analysis. All authors carefully read and approved the final version of the manuscript.

\section{Funding}

This project was funded by Shandong Forestry Science and Technology Innovation Project (LYCX06-2018-33). The funding body played no role in the design of the study and collection, analysis, and interpretation of data and in writing the manuscript.

\section{Availability of data and materials}

The datasets used and analysed during the current study are available from the corresponding author on reasonable request.

\section{Ethics approval and consent to participate}

Chrysanthemum materials of this study were provided by plant tissue culture room of Shandong Agricultural University. No field permission was necessary to collect the plant samples in this study. This experimental research on chrysanthemum complied with institutional, national, or international guidelines.

\section{Consent for publication}

Not applicable.

\section{Competing interests}

The authors declare that the research was conducted in the absence of any commercial or financial relationships that could be construed as a potential conflict of interest. The authors declare that they have no competing interests.

Received: 25 May 2019 Accepted: 9 October 2019

Published online: 25 October 2019

\section{References}

1. Shinoyama H, Aida R, Ichikawa H, Nomura Y, Mochizuki A. Genetic engineering of chrysanthemum (Chrysanthemum morifolium): current progress and perspectives. Plant Biotechnol. 2012;29(4):323-37.

2. Suvija NV, Suresh J. Evaluation of chrysanthemum (Chrysanthemum morifolium Ramat.) genotypes for loose flower, cut flower and pot mums. Int J Innov Res Adv Stud (IJIRAS). 2016;3(4):100-4.

3. Chen Y, Sun XZ, Zheng CS, Zhang S, Yang JH. Grafting onto Artemisia annua improves drought tolerance in chrysanthemum by enhancing photosynthetic capacity. Horticultural Plant J. 2018;4(03):117-25.

4. Davies FT, He C, Chau A, Heinz KM, Cartmill AD. Fertility affects susceptibility of chrysanthemum to cotton aphids: influence on plant growth, photosynthesis, ethylene evolution, and herbivore abundance. J Am Soc Hortic Sci. 2004;129(3):344-53.

5. Liu Y. Historical and modern genetics of plant graft hybridization. Adv Genet. 2006:56:101-29.

6. Mudge K, Janick J, Scofield S, Goldschmidt EE. A history of grafting. In: Janick J, editor. Horticultural reviews, vol. 35. Hoboken: John Wiley; 2009. p. 437-93.

7. Lee JM, Kubota C, Tsao SJ, Bie Z, Echevarria PH, Morra L, Oda M. Current status of vegetable grafting: diffusion, grafting techniques, automation. Sci Hortic. 2010;127:93-105

8. Gregory PJ, Atkinson CJ, Bengough AG, Else MA, FernandezFernandez F, Harrison RJ, Schmidt S. Contributions of roots and rootstocks to sustainable, intensified crop production. J Exp Bot. 2013;64:1209-22.

9. Deng Y, Chen S, Lu A, Chen F, Tang F, Guan Z, Teng N. Production andcharacterisation of the intergeneric hybrids between Dendranthemamorifolium and Artemisia vulgaris exhibiting enhanced resistance tochrysanthemum aphid (Macrosiphoniella sanbourni). Planta. 2010;231(3):693-703.

10. Zhang PJ, Broekgaarden C, Zheng SJ, Snoeren TAL, Van Loon JJA, Gols R, Dicke M. Jasmonate and ethylene signalling mediate whitefy-induced 
interference with indirect plant defence in Arabidopsis thaliana. New Phytol. 2013;197:1291-9.

11. Xi W, Yanmei Z, Caiyun W. Changes of protective enzyme activity in chrysanthemum grafted seedlings under high temperature stress. J Northwest Agric Forestry Univ (Nat Sci Ed). 2014;42(01):125-31.

12. Mahunu GK, Osei-Kwarteng M, Quainoo AK. Dynamics of graft formation in fruit trees: a review. Alban J Agric Sci. 2013;12(2):177-80.

13. Weimin F. Effects of grafting on stress resistance of chrysanthemum and cultivation techniques of cut chrysanthemum [D]. Nanjing Agricultural University, 2009.

14. Xia X, Shao Y, Jiang J, Ren L, Chen F, Fang W, Guan Z, Chen S. Gene expression profiles responses to aphid feeding in chrysanthemum (Chrysanthemum morifolium ). BMC Genomics. 2014;15(1):1050.

15. Li P, Song A, Gao C, Jiang J, Chen S, Fang W, Zhang F, Chen F. The overexpression of a chrysanthemum WRKY transcription factor enhances aphid resistance. Plant Physiol Biochem. 2015;95:26-34

16. Wang $Y$, Sheng L, Zhang H, Du X, An C, Xia X, Chen F, Jiang J, Chen S. CmMYB19 over-expression improves aphid tolerance in chrysanthemum by promoting lignin synthesis. Int J Mol Sci. 2017;18(3):619.

17. Smith CM, Boyko EV. The molecular bases of plant resistance and defense responses to aphid feeding: current status. Entomol Exp Appl. 2007;122(1):1-16.

18. Moran PJ, Cheng Y, Cassell $J$, Thompson GA. Gene expression profiling of Arabidopsis thaliana in compatible plant-aphid interactions. Arch Insect Biochem Physiol. 2002;51(4):182-203.

19. Lazebnik J, Frago E, Dicke M, van Loon JJA. Phytohormone mediation of interactions between herbivores and plant pathogens. J Chem Ecol. 2014; 40(7):730-41 Morkunas I, Mai VC, Gabryś B. Phytohormonal signaling in plant responses to aphid feeding. Acta Physiol Plant. 2011;33(6):2057-73.

20. Walling LL. Adaptive defense responses to pathogens and insects. Adv Bot Res. 2009;51:551-612.

21. Moran PJ, Thompson GA. Molecular responses to aphid feeding in Arabidopsis in relation to plant defense pathways. Plant Physiol. 2001;125(2): 1074-85.

22. Leszczynski B, Wright LC, Bakowski T. Effect of secondary plant-substances on winter-wheat resistance to grain aphid. Entomol Exp Appl. 1989;52(2): 135-9.

23. Koch K. Sucrose metabolism: regulatory mechanisms and pivotal roles in sugar sensing and plant development. Curr Opin Plant Biol. 2004;7:235-46.

24. Van den Ende W. Multifunctional fructans and raffinose family oligosaccharides. Front Plant Sci. 2013:4(247):1-11.

25. Shiratake K. Genetics of sucrose transporter in plants. Genes Genomes Genomics Glob Sci Books. 2007;1(1):73-80.

26. Morkunas I, Kozłowska M, Ratajczak L, Marczak $Ł$. Role of sucrose in the development of Fusarium wilt in lupine embryo axes. Physiol Mol Plant Pathol. 2007;70:25-37.

27. Sauer N. Molecular physiology of higher plant sucrose transporters. FEBS Lett. 2007;581(12):2309-17.

28. Wahl R, Wippel K, Goos S, Kämper J, Sauer N. A novel highaffinity sucrose transporter is required for virulence of the plant pathogen Ustilago maydis. PLoS Biol. 2010;8(2):e1000303

29. Lemoine R, La Camera S, Atanassova R, Dédaldéchamp F, Allario T, Portau N, Bonnemain J-L, Laloi M, Coutos-Thiévenot P, Maurousset L, Faucher M, Girousse C, Lemonnier P, Parrilla J, Durand M. Source-to-sink transport of sugar and regulation by environmental factors. Front Plant Sci. 2013;4(272):1-21.

30. Gould KS, Lister C. Flavonoid functions in plants. In: Andersen ØM, Markham KR, editors. Flavonoids: chemistry, biochemistryand applications. London, New York, Boca Raton: CRC Press; 2006. p. 397-441.

31. He J, Chen F, Chen S, Lv G, Deng Y, Fang W, Liu Z, Guan Z, He C. Chrysanthemum leaf epidermal surface morphology and antioxidant and defense enzyme activity in response to aphid infestation. J Plant Physiol. 2011;168(7):687-93.

32. Simmonds MSJ. Flavonoid-insect interactions: recent advances in our knowledge. Phytochemistry. 2003;6:21-30

33. Lattanzio V, Arpaia S, Cardinali A, Di Venere D, Linsalata V. Role of endogenous flavonoids in resistance mechanism of Vigna to aphids. J Agric Food Chem. 2000:48(11):5316-20.

34. He J. Resistance of pepper varieties to Bemisia tabaci (Gennadius): Yang Zhou University; 2016.

35. Reinhard H, Rupp H, Sager F, Streule M, Zoller O. Quinolizidine alkaloids and phomopsins in lupin seeds and lupin containing food. J Chromatogr A. 2006;1112:353-60. https://doi.org/10.1016/j.chroma.2005.11.079.
36. Ganzera M, Kruger A, Wink M. Determination of quinolizidine alkaloids in different Lupinus species by NACE using UV and MS detection. J Pharmaceut Biomed. 2010;53:1231-5. https://doi.org/10.1016/j.jpba.2010.05.030.

37. Wink M. Chemische Verteidigung der Lupinen: Zur biologischen Bedeutung der Chinolizidinalkaloide. Plant Syst Evol. 1985;150:65-81. https://doi.org/10. 1007/BF00985568.

38. Wink M. Plant-breeding-importance of plant secondary metabolites for protection against pathogens and herbivores. Theor Appl Genet. 1988;75: 225-33. https://doi.org/10.1007/Bf00303957.

39. Wink M, Meissner C, Witte L. Patterns of quinolizidine alkaloids in 56 species of the genus lupinus. Phytochemistry. 1995;38:139-53. https://doi.org/10. 1016/0031-9422(95)91890-D.

40. Pichersky E, Gershenzon J. The formation and function of plant volatiles: perfumes for pollinator attraction and defense. Curr Opin Plant Biol. 2002;5: 237-43.

41. Durrant WE, Dong X. Systemic acquired resistance. Annu Rev Phytopathol. 2004:42:185-209.

42. Stam JM, Kroes A, Li Y, Gols R, Van Loon JJA, Poelman EH, Dicke M. Plant interactions with multiple insect herbivores: from community to genes. Annu Rev Plant Biol. 2014;65:689-713.

43. Wei J, Van Loon JJA, Gols R, Menzel TR, Li N, Kang L, Dicke M. Reciprocal crosstalk between jasmonate and salicylate defence-signalling pathways modulates plant volatile emission and herbivore host-selection behaviour. J Exp Bot. 2014;65:3289-98.

44. Mewis I, Tokuhisa JG, Schultz JC, Appel HM, Ulrichs C, Gershenzon J. Gene expression and glucosinolate accumulation in Arabidopsis thaliana in response to generalist and specialist herbivores of different feeding guilds and the role of defence signaling pathways. Phytochem. 2006;67:2450-62.

45. Kusnierczyk A, Tran DHT, Winge P, Jorstad TS, Reese JC, Troczynska J, Bones AM. Testing the importance of jasmonate signalling in induction of plant defences upon cabbage aphid (Brevicoryne brassicae) attack. BMC Genomics. 2011;12:423.

46. White RF. Acetyl salicylic acid (aspirin) induces resistance to tobacco mosaic virus in tobacco. Virology. 1979;99(2):410-2.

47. Ward ER, Uknes SJ, Williams SC, Dincher SS, Wiederhold DL, Alexander DC, Ryals JA. Coordinate gene activity in response to agents that induce systemic acquired resistance. Plant Cell. 1991;3(10):1085-94.

48. Gaffney T, Friedrich L, Vernooij B, Negrotto D, Nye G, Uknes S, Ryals J. Requirement of salicylic acid for the induction of systemic acquired resistance. Science. 1993;261(5122):754-6.

49. Li Y, Song Z, Jin Z. J. Study on PPO, PAL and POD damage to early cowpea seedling leaves by cinerea rosae [J]. J Northwest Normal Univ (Nat Sci Ed). 2003;(03):61-64+67.

50. Ryals J, Weymann K. The Arabidopsis NIM1 protein shows homology to the mammalian transcription factor inhibitor IkB. Plant Cell. 1997;9:425-39.

51. Glazebrook J, Rogers EE. Isolation of Arabidopsis mutants with enhanced disease susceptibility by direct screening. Genetics. 1996;143:973-82.

52. Consatbel PC. A survey of herbivore indueible defensive proteins and phytochemicals. In: Agrawal AA, Tuzun S, Bent E, et al., editors. Induced defenses against pathogens and herbivores. St. Paul: Aps press; 1999. p. 137-66.

53. Bottcher C, Pollmann S. Plant oxylipins: plant responses to 12-oxophytodienoic acid are governed by its specific structural and functional properties. FEBS J. 2009;276:4693-704

54. Dave A, Hernandez ML, He Z, Andriotis VM, Vaistij FE, Larson TR, Graham IA. 12-oxo-phytodienoic acid accumulation during seed development represses seed germination in Arabidopsis. Plant Cell. 2011;23:583-99.

55. Yan J, Zhang C, Gu M, Bai Z, Zhang W, Qi T, Cheng Z, Peng W, Luo H, Nan F, Wang Z, Xie D. The Arabidopsis CORONATINE INSENSITIVE1 protein is a jasmonate receptor. Plant Cell. 2009;21:2220-36.

56. Voelckel C, Weisser W, Baldwin I. An analysis of plant-aphid interactions by different microarray hybridization strategies. Mol Ecol. 2004;13(10):3187-95.

57. Fidantsef A, Stout M, Thaler J, Duffey S, Bostock R. Signal interactions in pathogen and insect attack: expression of lipoxygenase, proteinase inhibitor II, and pathogenesis-related protein P4 in the tomato, Lycopersicon esculentum. Physiol Mol Plant Pathol. 1999:54(3):97-114.

58. Cheng Z, Xue Q. Plant protease inhibitor gene structure, regulation and control of pest control strategy. Genetics. 2003;30(8):790-6.

59. Wang Z, Yang B, Zheng Z. Advances in genetic Engineering of Plant Protease Inhibitors against insect pests. J Plant Prot. 2001;28(1):83-7.

60. Argandona V, Chaman M, Cardemil L, Munoz O, Zuniga G, Corcuera L. Ethylene production and peroxidase activity in aphid-infested barley. $J$ Chem Ecol. 2001;27(1):53-68. 
61. Divol F, Vilaine F, Thibivilliers S, Amselem J, Palauqui J-C, Kusiak C, Dinant S. Systemic response to aphid infestation by Myzus persicae in the phloem of Apium graveolens. Plant Mol Biol. 2005;57(4):517-40.

62. Boyko EV, Smith CM, Thara VK, Bruno JM, Deng Y, Starkey SR, Klaahsen DL. Molecular basis of plant gene expression during aphid invasion: wheat Ptoand Pti-like sequences are involved in interactions between wheat and Russian wheat aphid (Homoptera: Aphididae). J Econ Entomol. 2006;99(4): $1430-45$.

63. Kieber JJ, Rothenberg M, Roman G, et al. CTR1, a negative regulator of the ethylene response pathway in Arabidopsis, encodes a member of the Raf family of protein kinases. Cell. 1993;72(3):427-41.

64. Ecker JR. The ethylene signal transduction pathway in plants. Science. 1995; 268(5211):667-75.

65. Alonso J, Hirayama T. EIN2, a bifunctional transducer of ethylene and stress responses in Arabidopsis. Science. 1999;284:2148-52

66. Jones JDG, Dangl JL. The plant immune system. Nature. 2006;444(7117): 323-9.

67. Zipfel C. Plant pattern-recognition receptors. Trends Immunol. 2014;35(7): 345-51.

68. Melotto M, Underwood W, He SY. Role of stomata in plant innate immunity and foliar bacterial diseases. Annu Rev Phytopathol. 2008;46: $101-22$.

69. Grabherr MG, Haas BJ, Yassour M, Levin JZ, Thompson DA, Amit I, Adiconis X, Fan L, Raychowdhury R, Zeng Q, et al. Full-length transcriptome assembly from RNA-Seq data without a reference genome. Nat Biotechnol. 2011;29: 644-52.

70. Foyer $\mathrm{CH}$, Verrall SR, Hancock RD. Systematic analysis of phloem-feeding insect-induced transcriptional reprogramming in Arabidopsis highlights common features and reveals distinct responses to specialist and generalist insects. J Exp Bot. 2014;66(2):495-12.

71. Liu X. Study on the regulation and mechanism of calcium / calmodulin dependent protein kinase II and MHC class II molecules on the innate immune response of macrophages and dendritic cells triggered by TLR: Second military Medical University; 2009.

72. Kaloshian I, Kinsey M, Ullman D, Williamson V. The impact of Meu1mediated resistance in tomato on longevity, fecundity and behavior of the potato aphid, Macrosiphum euphorbiae. Entomologia Exp Appl. 1997;83(2): 181-7.

73. Rossi M, Goggin FL, Milligan SB, Kaloshian I, Ullman DE, Williamson VM. The nematode resistance gene mi of tomato confers resistance against the potato aphid. Proc Natl Acad Sci. 1998;95(17):9750-4.

74. Pauquet J, Burget E, Hagen L, Chovelon V, Menn A, Valot N, Desloire S, Caboche M, Rousselle P, Pitrat M. Map-based cloning of the Vat gene from melon conferring resistance to both aphid colonization and aphid transmission of several viruses. In: Olomouc LA, Paris HS, editors. Proceedings of the 8th EUCARPIA Meeting on Cucurbit Genetics and Breeding: 12-17 July 2004; 2004. p. 325-9.

75. Brotman Y, Silberstein L, Kovalski I, Perin C, Dogimont C, Pitrat M, Klingler J, Thompson G, Perl-Treves R. Resistance gene homologues in melon are linked to genetic loci conferring disease and pest resistance. Theor Appl Genet. 2002;104(6-7):1055-63.

76. Chang S, Puryear J, Cairney J. A simple and efficient method for isolating RNA from pine trees. Plant Mol Biol Rep. 1993;11:113-6.

77. Moriya Y, Itoh M, Okuda S, Yoshizawa AC, Kanehisa M. KAAS: an automatic genome annotation and pathway reconstruction server. Nucleic Acids Res. 2007;35:W182-5

78. Götz S, García-Gómez JM, Terol J, Williams TD, Nagaraj SH, Nueda MJ, Robles M, Talón M, Dopazo J, Conesa A. High-throughput functional annotation and data mining with the Blast2GO suite. Nucleic Acids Res. 2008:36:3420-35

79. Trapnell C, Williams BA, Pertea G, Mortazavi A, Kwan G, van Baren MJ, Salzberg SL, Wold BJ, Pachter L. Transcript assembly and quantification by RNA-Seq reveals unannotated transcripts and isoform switching during cell differentiation. Nat Biotechnol. 2010;28:511-5.

80. Yekutieli D, Benjamini Y. Resampling-based false discovery rate controlling multiple test procedures for correlated test statistics. J Stat Plann Inference. 1999;82:171-96.

81. Xu H, Yu C, Xia X, Li M, Li H, Yu W, Wang S, Wang C, Ma Y, Zhou G. Comparative transcriptome analysis of duckweed ( Landoltia punctata ) in response to cadmium provides insights into molecular mechanisms underlying hyperaccumulation. Chemosphere. 2018;190:154-65.
82. Gao J. Guidance on plant physiology experiment. Beijing: Higher Education Press; 2006.

83. Kong X. Plant physiological experimental technology. Beijing: China Agriculture Press; 2008

84. Jia ZS, Tang MC, Wu JM. The determination of flavonoid contents in mulberry and their scavenging effects on superoxide radicals. Food Chem. 1999;64(4):555-9.

85. Zhang M, Gu Y, Zhang YH, Zhao JC, Peng Y, Xu CT, Xie Q, Xia JH, Zhang JJ, Lu LM. Differences in lipid oxygenase activity and gene expression levels in tobacco leaves from different growing areas in sichuan province. Guizhou Agric Sci. 2017:45(08):9-12 (in Chinese with English abstract)

\section{Publisher's Note}

Springer Nature remains neutral with regard to jurisdictional claims in published maps and institutional affiliations.
Ready to submit your research? Choose BMC and benefit from:

- fast, convenient online submission

- thorough peer review by experienced researchers in your field

- rapid publication on acceptance

- support for research data, including large and complex data types

- gold Open Access which fosters wider collaboration and increased citations

- maximum visibility for your research: over $100 \mathrm{M}$ website views per year

At BMC, research is always in progress.

Learn more biomedcentral.com/submissions 